\title{
The AKT1/NF-kappaB/Notch1/PTEN axis has an important role in chemoresistance of gastric cancer cells
}

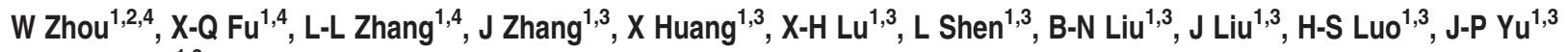 \\ and $\mathrm{H}-\mathrm{G} \mathrm{Y \textrm {u } ^ { * , 1 , 3 }}$
}

The inherent resistance of tumors to DNA damage often limits the efficacy of chemotherapy. The aim of this work is to explore the potential mechanism for development of chemoresistance in gastric cancer. Our data revealed that AKT1 mRNA and protein expression were induced by doxorubicin (a chemotherapeutic agent); the doxorubicin-induced AKT1 expression and activation increased the binding of NF-kappaB on Notch1 DNA promoter and then promoted the Notch1 transcription and expression; enhanced expression of Notch1 further upregulated PTEN expression through CBF-1 binding to PTEN DNA promoter; and inhibition of AKT1 expression and activity sensitized the gastric cancer cell to doxorubicin treatment in cultured gastric cancer cell lines and xenograft nude mice gastric cancer model. Furthermore, our data demonstrated that both Notch1 and PTEN were absent or minimally expressed in gastric cancer tissue but abundant in paired normal gastric mucosa, and the expression of Notch1 correlated with that of PTEN. Together, these novel results suggested that a novel AKT1/NF-kappaB/Notch1/PTEN axis has an important role in the development of chemoresistance in gastric cancer. Notch1 has an anti-cancer role in gastric cancer.

Cell Death and Disease (2013) 4, e847; doi:10.1038/cddis.2013.375; published online 10 October 2013

Subject Category: Cancer

DNA-damaging insults and imposing a strong apoptotic trigger in rapidly dividing tumor cells is the main strategy of anti-cancer chemotherapy. ${ }^{1}$ Doxorubicin, which interferes with the action of topoisomerase II $\alpha$ and induces DNA double-strand breaks, has gained broad application for chemotherapy of solid cancer, including gastric cancer. ${ }^{2,3}$ However, like other chemotherapeutic agents, the efficacy of doxorubicin is severely limited because of chemoresistance.

The apoptotic capacity has been widely used for determining the response of cancer cell to chemotherapeutic agent. ${ }^{4-6}$ Cell apoptosis is a tightly regulated process under the control of numerous signal transduction pathways, such as phosphatidylinositol 3-kinase (PI3K)/AKT pathway. ${ }^{7}$

AKT (also named protein kinase B) represents a subfamily of the serine/threonine kinase. ${ }^{8}$ Our previous work has described that constitutive and inducible PI3K/AKT activities involve in chemoresistance of gastric cancer cells through a number of targets, including NF-kappaB $(\mathrm{NF} \kappa \mathrm{B})$, forkhead transcription factors, caspase-3, and -9; downregulation of $\mathrm{PI} 3 \mathrm{~K} / \mathrm{AKT}$ activities through overexpression of PTEN gene sensitizes gastric cancer cells to chemotherapeutic drugs. $^{9}$
PTEN (phosphatase and tensin homologue, deleted on chromosome 10) is one of the most frequently lost tumor suppressors in human cancer. ${ }^{10}$ Many times, the PTEN gene is intact but appears to be transcriptionally silent. PTEN protein has a very short half-life and its degradation appears to be further accelerated by some genetic alterations in cancer cells. ${ }^{11}$ Thus, the de novo synthesis of PTEN protein is critical to retain the PTEN function. Our previous research ${ }^{9}$ has identified a decreased constitutive PTEN transcription and protein expression in human gastric cancer tissues. Recently, PTEN gene expression is found to be induced by etoposide treatment ${ }^{12}$ and UV irradiation. ${ }^{13}$ It is reported that PTEN expression can be regulated by Notch-1 signaling through binding CBF-1 to PTEN promoter. ${ }^{14-16}$

Human Notch receptor family has four family members termed Notch1, 2, 3, and 4. Five human ligands, including Jagged-1, Jagged-2, Delta 1, Delta 3, and Delta 4, have already been identified. ${ }^{17}$ After ligand binding, a number of modifications occurred in Notch receptors, including a proteolytic cleavage operated by a $\gamma$-secretase complex that ultimately releases the intracellular portion (active form) of Notch receptors (Notch intracellular domain (NICD)) from the plasma membrane. Therefore, Notch-1 association to CBF-1

\footnotetext{
${ }^{1}$ Department of Gastroenterology, Renmin Hospital of Wuhan Univeristy, 430060 Wuhan, China; ${ }^{2}$ Department of Gastroenterology, The First Hospital of Wuhan, 43000 Wuhan, China and ${ }^{3}$ Institute for Gastroenterology and Hepatology, Renmin Hospital of Wuhan Univeristy, 430060 Wuhan, China

${ }^{*}$ Corresponding author: H-G Yu, Department of Gastroenterology, Renmin Hospital of Wuhan University and Institute for Gastroenterology and Hepatology, Wuhan University, Jiefang Road 238, Wuhan 430060, China. Tel: +86 27 88041911 82135; Fax: +86 27 88042292; E-mail: yhg_rmhwh@163.com

${ }^{4}$ These authors contributed equally to this work.

Keywords: AKT1; NF-kappaB; Notch-1; PTEN; gastric cancer

Abbreviation: ChIP, chromatin immunoprecipitation; NF $\kappa B$, NF-kappaB; Scr, Scrambled; shRNA, short-hairpin RNA; siRNA, small interference RNA; PBS, phosphatebuffered saline

Received 12.6.13; revised 03.8.13; accepted 06.8.13; Edited by A Stephanou
} 
converts the latter from a transcriptional repressor into a transcriptional activator. ${ }^{18}$ Previous research has observed that Notch-1 expression can be upregulated by hyperactivated $\mathrm{PI} 3 \mathrm{~K} / \mathrm{Akt}$ signaling through $\mathrm{NF} \kappa \mathrm{B}$ activity. ${ }^{19}$

In this study, we demonstrated that AKT1 mRNA and protein expression were induced by doxorubicin; reactive oxygen species (ROS)/JAK2/STAT3 were the upstream regulators of AKT1 expression; doxorubicin-induced AKT1 expression and activation led to upregulation of Notch1 expression through increasing $\mathrm{NF}_{\kappa} \mathrm{B}$ DNA binding activity, this increased Notch1 expression further promoted PTEN expression through CBF-1 binding to PTEN DNA promoter. Our data revealed an important role of $\mathrm{AKT}_{1 / \mathrm{NF}} \kappa \mathrm{B} / \mathrm{Notch}_{1 /}$ PTEN axis in chemoresistance of gastric cancer cell.

\section{Results}

Doxorubicin promoted expression of AKT1, Notch1, and PTEN in human gastric cancer cells. As shown in Figure 1a, doxorubicin time-dependently induced expression of AKT1, phospho-AKT (Ser473), Notch1, and PTEN in MKN-28, a human gastric cancer cell line. To exclude the cell-specific event, the mRNA and protein expression of the above targets were investigated in other four human gastric cancer cell lines (AGS, SGC-7901, MKN-45, and BGC-823), similar results were achieved (Figure 1b). To further verify the above findings in vivo, we implanted the MKN-28 cells on the flank of BALB/c-nude mice. In MKN-28 xenograft tumor, the mRNA and protein expression of AKT1, Notch1,

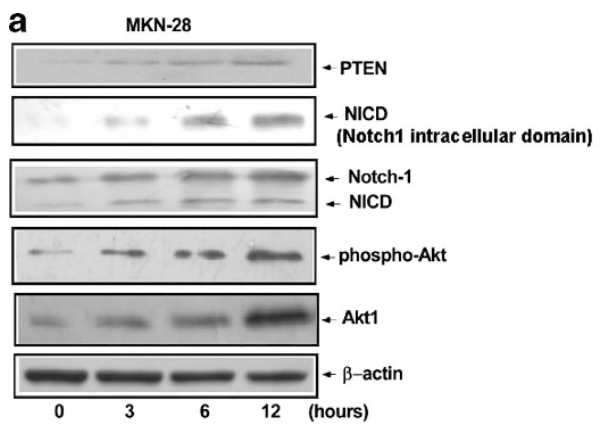

b
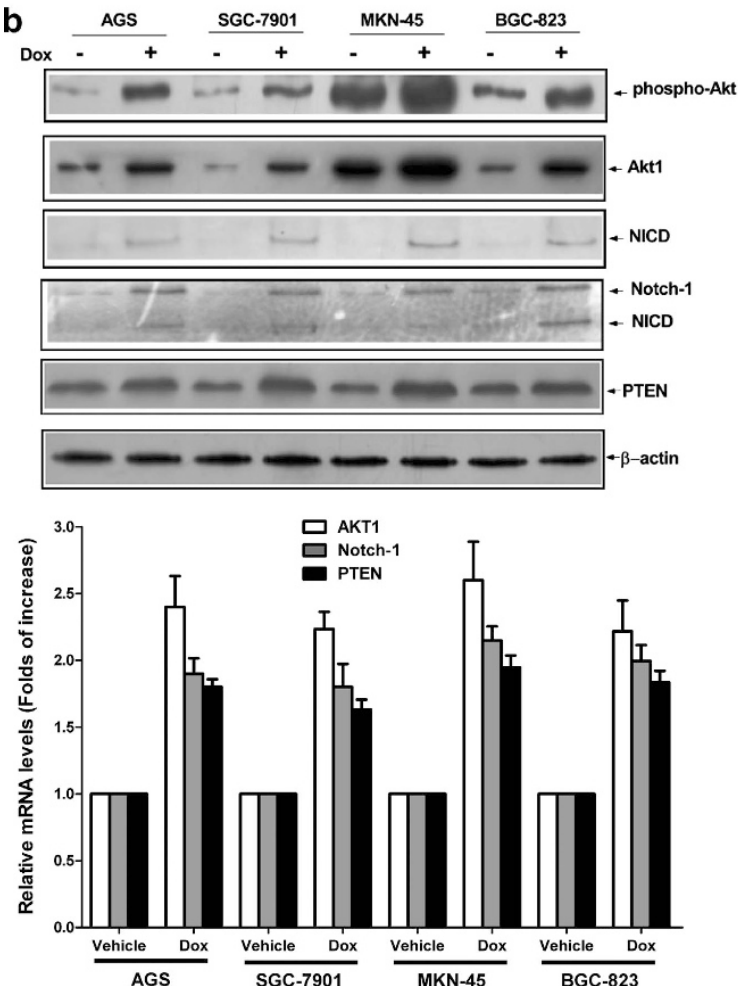

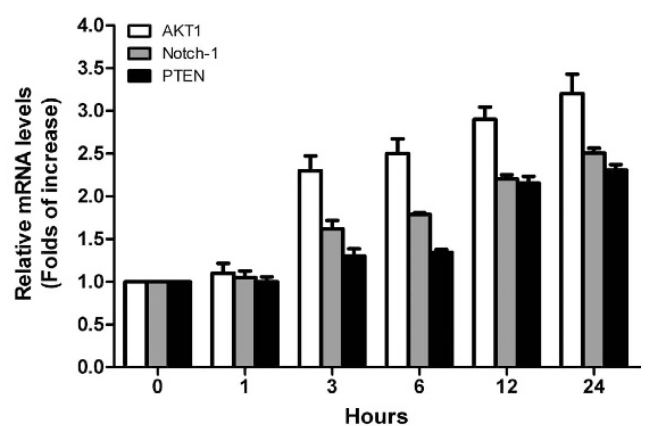

C
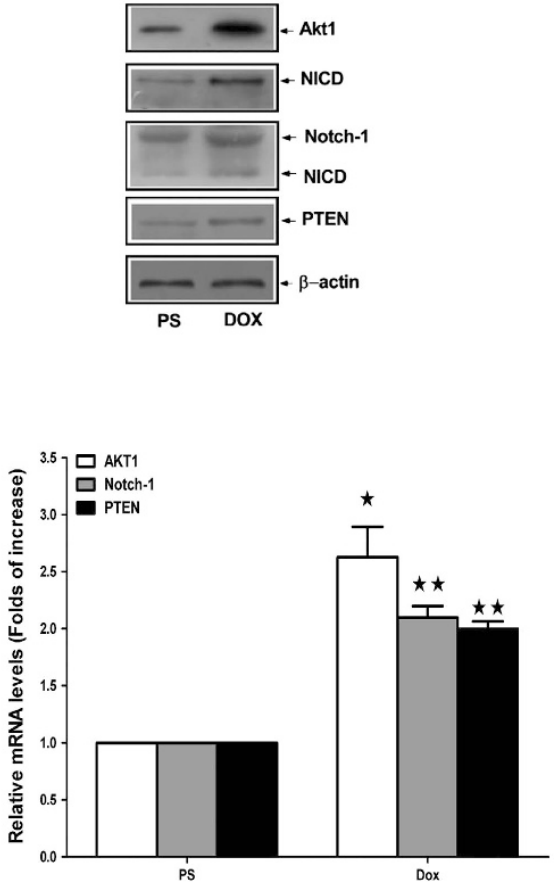

Figure 1 Elevated expression of AKT1, Notch-1, and PTEN in human gastric cancer cells after treatment of doxorubicin. (a) The MKN-28 cells were incubated with $3 \mu \mathrm{M}$ doxorubicin for various time courses, and the protein and mRNA levels of AKT1, Notch1, and PTEN were determined by immunoblotting and real-time RT-PCR, respectively. Values are the mean \pm S.D. from three different experiments. (b) The protein and mRNA levels of AKT1, Notch1, and PTEN in the indicated human gastric cancer cell lines after $12 \mathrm{~h}$ treatment of doxorubicin $(3 \mu \mathrm{M})$ were determined by immunoblotting and real-time RT-PCR, respectively. Values are the mean \pm S.D. from three different experiments. (c) Nude mice bearing MKN-28 xenograft tumor $\left(\times 100 \mathrm{~mm}^{3}\right)$ were intraperitoneally administered with physiological saline (PS) and $8 \mathrm{mg} / \mathrm{kg}$ doxorubicin, respectively, once for 4 days. All nude mice were killed at day 21 and the protein and mRNA levels of AKT1, Notch-1, and PTEN in xenograft tumors were determined by immunoblotting and real-time RT-PCR, respectively. Values are the mean \pm S.D. from three different experiments. Statistical significance is compared with PS group. $\star P<0.05,{ }^{\star} \star P<0.01$. In all the above experiments, immunoblotting results of $\beta$-actin were used to show equal loading 
and PTEN were obviously increased after doxorubicin treatment (Figure 1c). Because of the in-parallel upregulation induced by doxorubicin, it was reasonable to ask if there existed a functional linkage among AKT1, Notch1, and PTEN.

AKT1 regulated the expression of Notch1 and PTEN through NF $\boldsymbol{\kappa}$ B pathway. First, MKN-28 cells were treated with LY294002, the well-known PI3K inhibitor, as described in the Methods section in order to determine the role of PI3K/AKT signaling in gastric cancer cells induced by doxorubicin. LY294002 could inhibit doxorubicin-induced protein levels of phosphorylation of AKT, Notch1, and PTEN but had no effect on AKT1 (Figure 2b).

To investigate the possible linkage among AKT1, Notch1 and PTEN, AKT1 expression in MKN-28 cells was knocked down using lentiviral-mediated short-hairpin RNA (shRNA). $A$ recent research ${ }^{19}$ has suggested that AKT regulated the expression of Notch1 through $\mathrm{NF}_{\kappa} \mathrm{B}$ pathway. Our data demonstrated that AKT1 knockdown obviously decreased both constitutive and doxorubicin-induced mRNA and protein levels of Notch1 and PTEN (Figure 2a). As shown in Figures $2 c$ and d, knockdown of AKT1 expression inhibited NF $\kappa$ B DNA binding activity and also decreased the DNA binding activity of CBF-1 on PTEN promoter. CBF-1 is the main transcriptional effector of Notch1 receptor activation and functions as a Notch-responsive transcriptional switch. ${ }^{20}$ Taken together, our data imply that in gastric cancer cells Notch1 and PTEN were downstream targets of $\mathrm{AKT}_{1} / \mathrm{NF}_{\kappa} \mathrm{B}$ pathway; transcription factor $\mathrm{NF}_{\kappa} \mathrm{B}$ was a positive regulator of Notch-1 transcription.

Our data also demonstrated that both knockdown of AKT1 expression and using LY294002 significantly promoted the basal and doxorubicin-induced apoptotic rate of cultured gastric cancer cells (Figure 2e). In addition, the activity of caspase-3 was detected using a Caspase-3 Colorimetric Assay Kit (Figure 2f). We also found that inhibition of PI3K/AKT pathway with either LY294002 or AKT1 shRNA led to enhanced doxorubicin-induced caspase-3 activity. These results implied that the mitochondria-mediated apoptosis pathway was involved when the expression of AKT1 was downregulated (or inhibition of AKT activation).

NF $\kappa$ B subunit p65 was the transcription factor that bound to the Notch1 promoter and regulated the transcription of Notch1 gene. To further determine the promoter region required for transcriptional activity of the Notch1 gene and to define the cis-elements responsible for the promoter activity, the $5^{\prime}$-flanking $2.2 \mathrm{~kb}$ region of Notch1 gene was cloned into a luciferase reporter, followed by promoter activity assays in MKN-28 cells. After computer analysis with the TFSEARCH program, two potential $\mathrm{NF}_{\kappa} \mathrm{B}$ binding sites ( $\mathrm{NF}_{\kappa} \mathrm{B}$-up: from -1995 to -1986 ; NF $\kappa \mathrm{B}-\mathrm{low}$ : from -1978 to -1969$)$ were identified in the promoter region of Notch1 gene (Figure $3 a$ ).

Five deletion promoter constructs of the $2.2 \mathrm{~kb}$ Notch 1 promoter vector ( -2002 to $-1 \mathrm{bp}$ ) were generated through its $5^{\prime}$ upstream sequence deletions (Figure $3 \mathrm{~b}$ ) and then transfected into MKN-28 cells. Our data revealed that the region from -2002 to $-1(\mathrm{P}-2002)$ from the start of transcription had the maximal promoter activity in MKN-28 cells (Figure 3c), and the Notch1 promoter activity was gradually decreased in the $\mathrm{P}-1985, \mathrm{P}-1962, \mathrm{P}-1482$, and P-960 constructs compared with the P-2002 construct. These results indicated that the cis-regulatory elements that were required for the Notch1 transcriptional activity are mainly located in the core region from -2002 to -1 upstream of the transcription start site.

The doxorubicin-induced luciferase activity was significantly blocked by AKT1 shRNA, pyrrolidinedithiocarbamic acid (PDTC), and p65 small interference RNA (siRNA) in $\mathrm{P}-2262, \mathrm{P}-2002$, and $\mathrm{P}-1985$, which contain one or two $\mathrm{NF} \kappa \mathrm{B}$ sites, but not in the other three constructs (P-1962, P-1482, and $\mathrm{P}-962$ ) without $\mathrm{NF} \kappa \mathrm{B}$ binding site (Figure $3 \mathrm{c}$ ). Meanwhile, mutation in one or two NF $\kappa$ B binding sites also decreased or even blocked the doxorubicin-induced luciferase activity.

Electrophoretic mobility shift assay (EMSA) analysis was also used to determine the role of $\mathrm{NF} \kappa \mathrm{B}$ in Notch-1 transcription. Oligonucleotides, containing wild or mutant $\mathrm{NF} \kappa \mathrm{B}$ binding sites were synthesized. Our data demonstrated that $\mathrm{NF} \kappa \mathrm{B}$ effectively bound to oligonucleotides containing wild-type $\mathrm{NF} \kappa \mathrm{B}$ binding sites but not to those with mutations (Figure 3d). The supershift experiment showed that both p65 and p50 antibodies induce supershift in MKN-28 cells (Figure 3d).

To further confirm the results achieved in deletion analysis and EMSA, chromatin immunoprecipitation (ChIP) assays was also carried out in MKN-28 cells. Our data suggested that p65 bound to either the upper or lower $\mathrm{NF}_{\kappa} \mathrm{B}$ binding site, while knockdown of AKT1 inhibited the binding of p65 on both $\mathrm{NF}_{\kappa} \mathrm{B}$ binding sites (Figure $3 \mathrm{e}$ ). These results were the further evidence of the promoter activity as shown in Figure 3c.

All these strongly indicated that doxorubicin-induced AKT1 activation promoted the transcription and expression of Notch1 through binding of $\mathrm{NF}_{\kappa} \mathrm{B}$ on Notch1 promoter region.

In addition, as shown in Figure $3 \mathrm{f}$, administration of PDTC $(50 \mu \mathrm{M})$ significantly improved doxorubicin induced apoptosis and caspase- 3 activity in MKN-28 cells.

Notch1 regulated doxorubicin-induced PTEN expression through CBF-1. Previous studies ${ }^{14-16}$ have reported that constitutively active Notch1 results in increased PTEN protein expression, and PTEN is regulated transcriptionally by the Notch1 signaling pathway through the CBF-1 transcription factor. Others observed an increased DNA binding activity of CBF-1 in myeloma cells that was promoted by Notch 1 activation. ${ }^{21}$ Our present data revealed that Notch1 knockdown downregulated the constitutive and doxorubicininduced mRNA and protein level of PTEN; results of EMSA and ChIP analyses suggested that Notch1 knockdown inhibited the DNA binding capability of CBF-1 to the minimal PTEN promoter (Figures $4 a-C$ ). These results indicated that doxorubicin promoted PTEN transcription through mediation of Notch1 and its downstream target CBF-1.

Notch1 can function as a tumor promoter or a suppressor depending on the cell type and context. ${ }^{22-26}$ In our series, knockdown of Notch1 expression decreased the basal and induced apoptosis in gastric cancer cells, which reveals a pro-apoptotic function of Notch1 here. To further address the role of Notch 1 in gastric cancer, the protein expression of Notch1 was detected in 22 gastric cancer tissues and the paired normal mucosa using immunohistochemistry. 
a
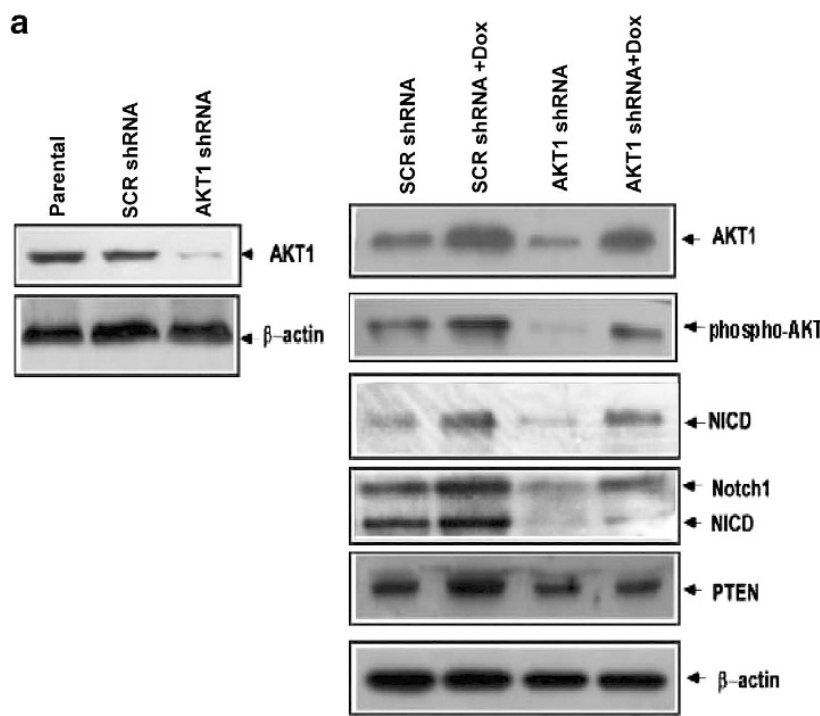

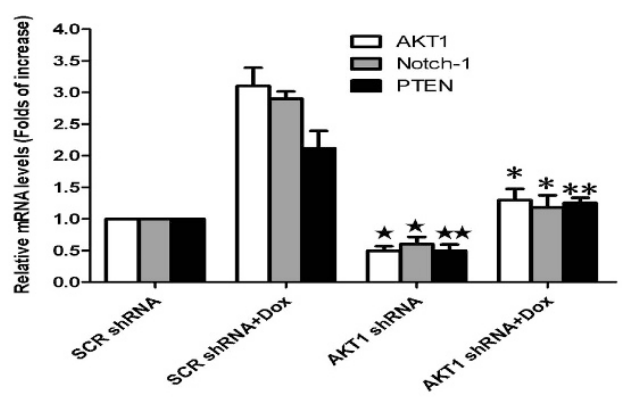

b

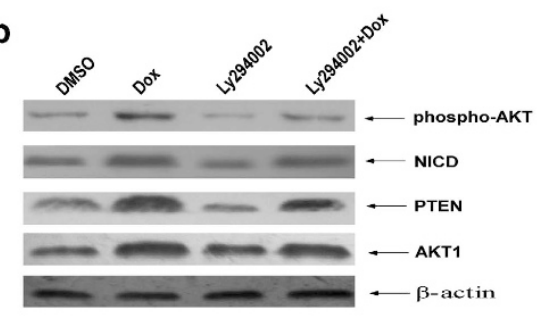

C
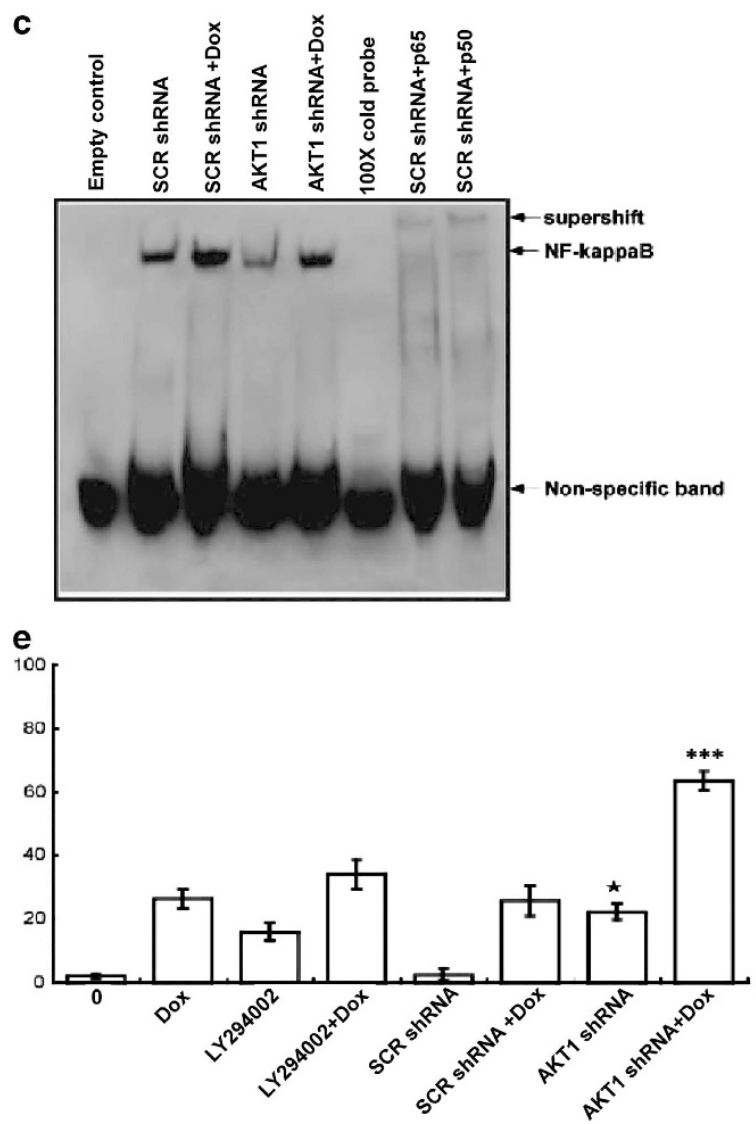

d
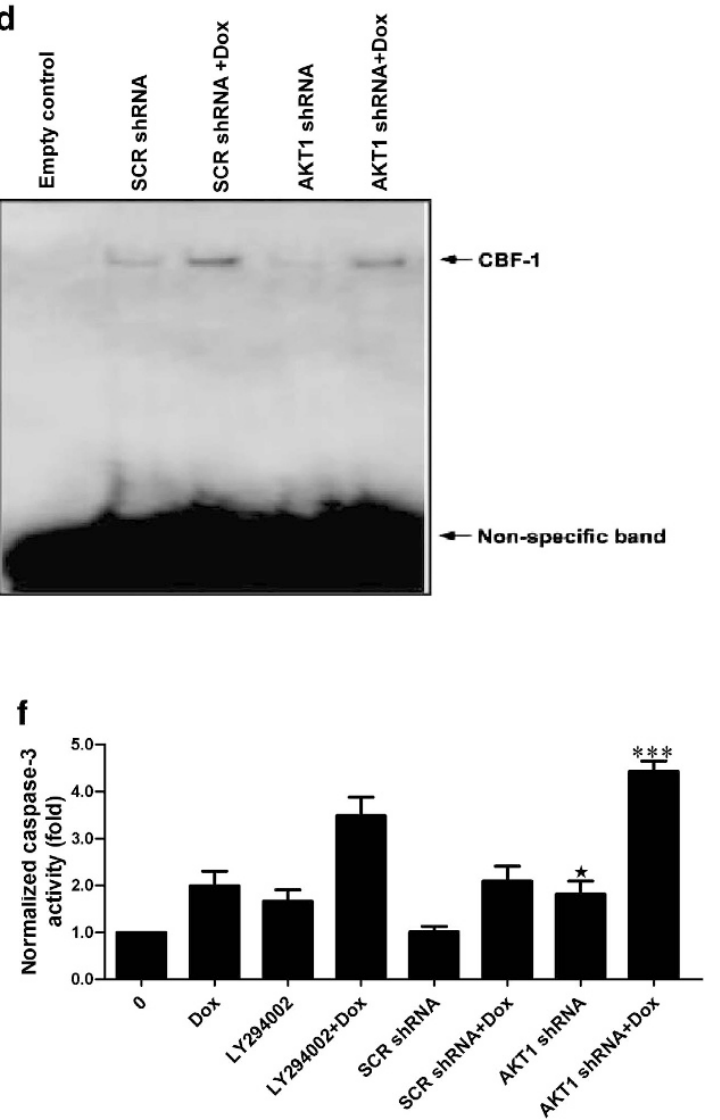

Figure 2 AKT1 regulated Notch-1 and PTEN expression through NFKB and had an anti-apoptotic role in gastric cancer cells. (a) Lysate from MKN-28 cells (parental), MKN-28 cells expressing lentiviral scramble shRNA (SCR shRNA), or lentiviral AKT1 shRNA were analyzed by anti-AKT1 blotting. The MKN-28 cells expressing lentiviral SCR shRNA or lentiviral AKT1 shRNA were treated with PS or $3 \mu \mathrm{M}$ doxorubicin for $12 \mathrm{~h}$, respectively. The protein and mRNA levels of AKT1, Notch1 and PTEN were detected by immunoblotting and real-time RT-PCR. Immunoblotting results of $\beta$-actin were used to show equal loading. Values are the mean \pm S.D. from three different experiments. ${ }^{\star} P<0.05,{ }^{\star}{ }^{\star} P<0.01$ versus SCR shRNA group; ${ }^{*} P<0.05,{ }^{\star}{ }^{\star} P<0.01$ versus SCR shRNA + Dox group. (b) Effect of doxorunicin and LY294002 (10 $\left.\mu \mathrm{M}\right)$ on expression of AKT1, p-AKT (473), NICD, and PTEN. Immunoblotting results of $\beta$-actin were used to show equal loading. (c) The MKN-28 cells expressing lentiviral SCR shRNA or lentiviral AKT1 shRNA were treated with PS or $3 \mu \mathrm{M}$ doxorubicin for $12 \mathrm{~h}$, respectively. The DNA binding capability of NF $\kappa$ B was detected by EMSA analysis. (d) The MKN-28 cells and MKN-28 cells expressing lentiviral SCR shRNA or lentiviral AKT1 shRNA were treated with PS or $3 \mu \mathrm{M}$ doxorubicin for $12 \mathrm{~h}$, respectively. The DNA binding capability of CBF-1 on PTEN minimal promoter was detected by EMSA analysis. (e) MKN-28 cells' preincubation with DMSO or $10 \mu \mathrm{M} \mathrm{LY} 294002$ and MKN-28 cells expressing lentiviral SCR shRNA or lentiviral AKT1 shRNA were treated with PS or $3 \mu \mathrm{M}$ doxorubicin for $12 \mathrm{~h}$, respectively. Cell apoptosis was determined by flow cytometry. ${ }^{\star} P<0.05$, versus SCR shRNA group. ${ }^{* \star *} P<0.01$ versus SCR shRNA + Dox group. (f) Analysis of relative caspase-3 activity in cells. Normalized caspase-3 activity. All experiments were performed in triplicate. ${ }^{\star} P<0.05$, versus SCR shRNA group. ${ }^{\star \star \star} P<0.01$ versus SCR shRNA + Dox group 


\section{a}

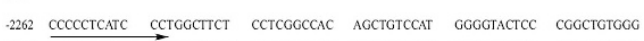

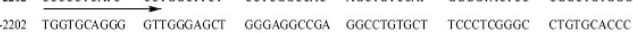

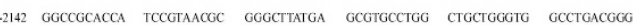

-2082 TGGaCACCGA ATGGGCCACT CTCTTCTCTG CTGGTAGAGG ATGGAGGCCC AagGtGGaGG

2022 tgCtGTCGGC ACAGCTGGGG CAGACCAGGG GAGACCCCCT atCCAGGGAT CCCCTCCTCC

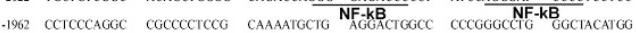

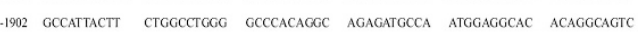

\begin{tabular}{llllll}
-1842 & GCACCCGCAC CCGATCAGCA CCAGGCCTGA GGCCTTCGG & cCtCCCTATG & $\frac{\text { CCCCACCCCA }}{\text {-1782 }}$ CCCCCACCCA \\
\hline
\end{tabular}

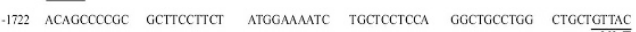

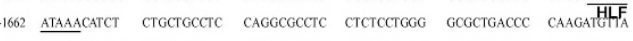

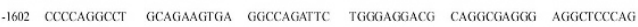

-1542 CAGCAGCTAC AGGGGCGGGa CAGGCCGCCT GCACTGGCTG TTTCCAGAGT GCTCAGCATT

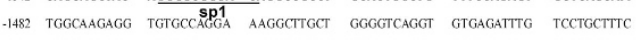

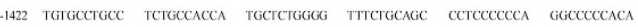

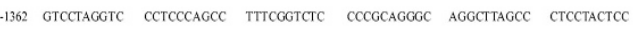

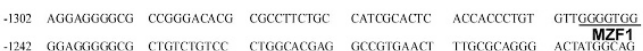

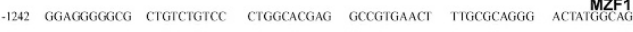

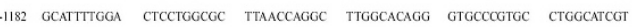

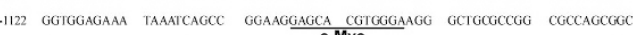

-1062 AGATCCGCCC GACCCGTTTG TGCTTTCTGG C-MYGCCACACTTA GGCAGGCGGC GCCCGGGCAG

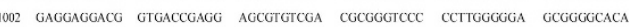

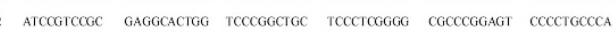

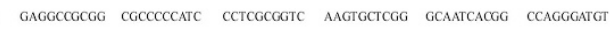

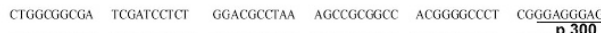

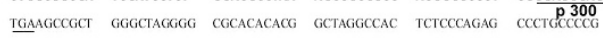

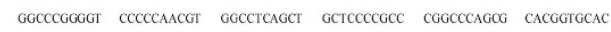

ACGGCTGTCC GCGGCCTCGC CCTCCCCATT CCGCCCCGGG стCCTCCGCT tattCACATG

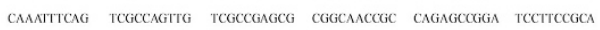

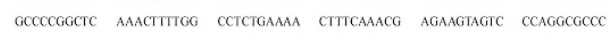

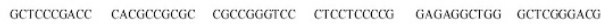

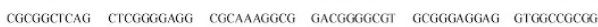

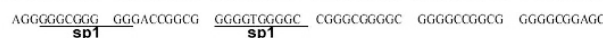

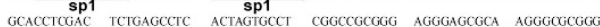

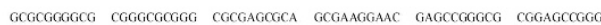

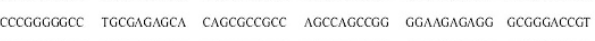

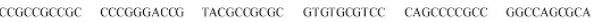

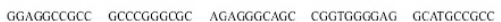

b
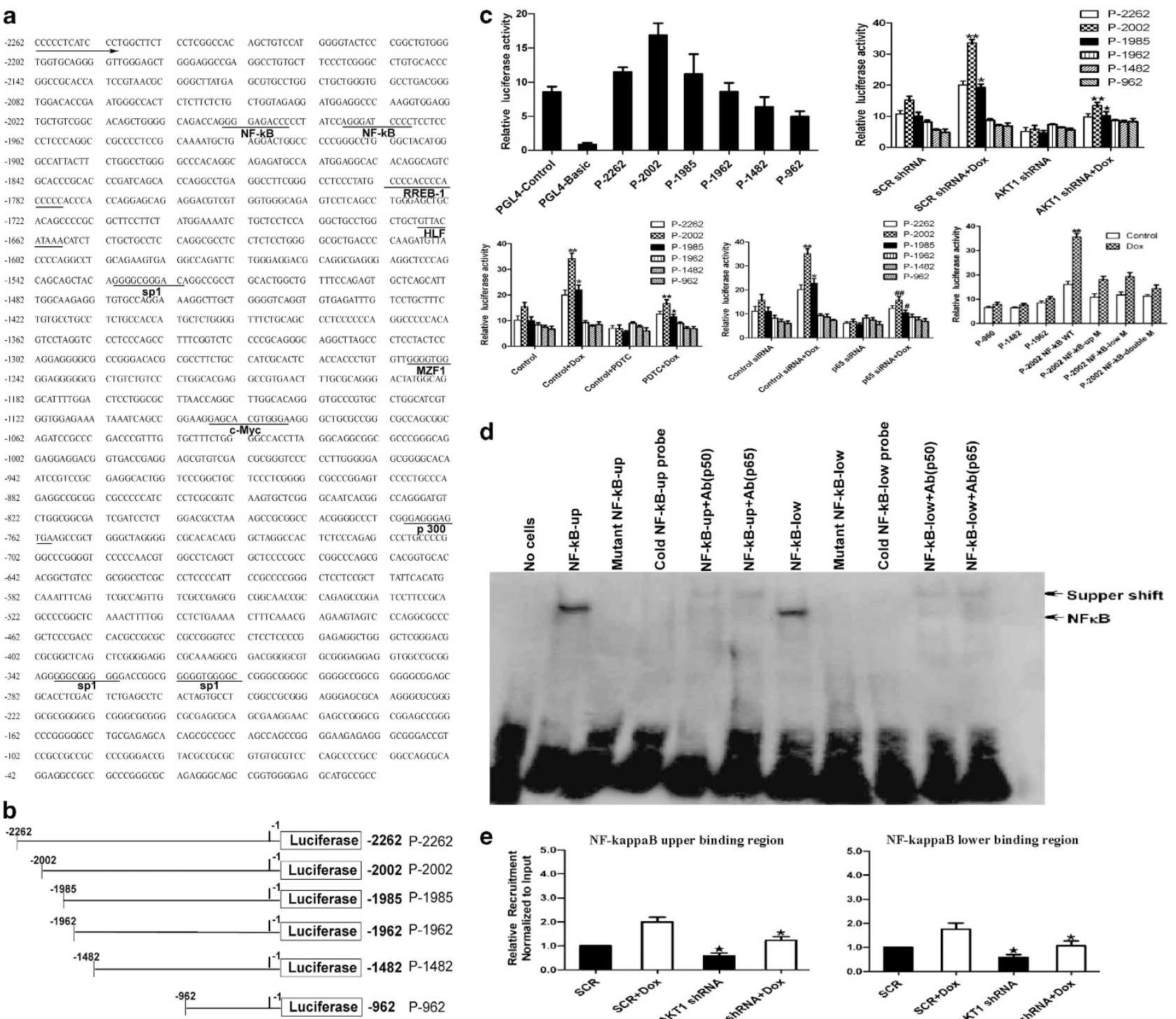

e
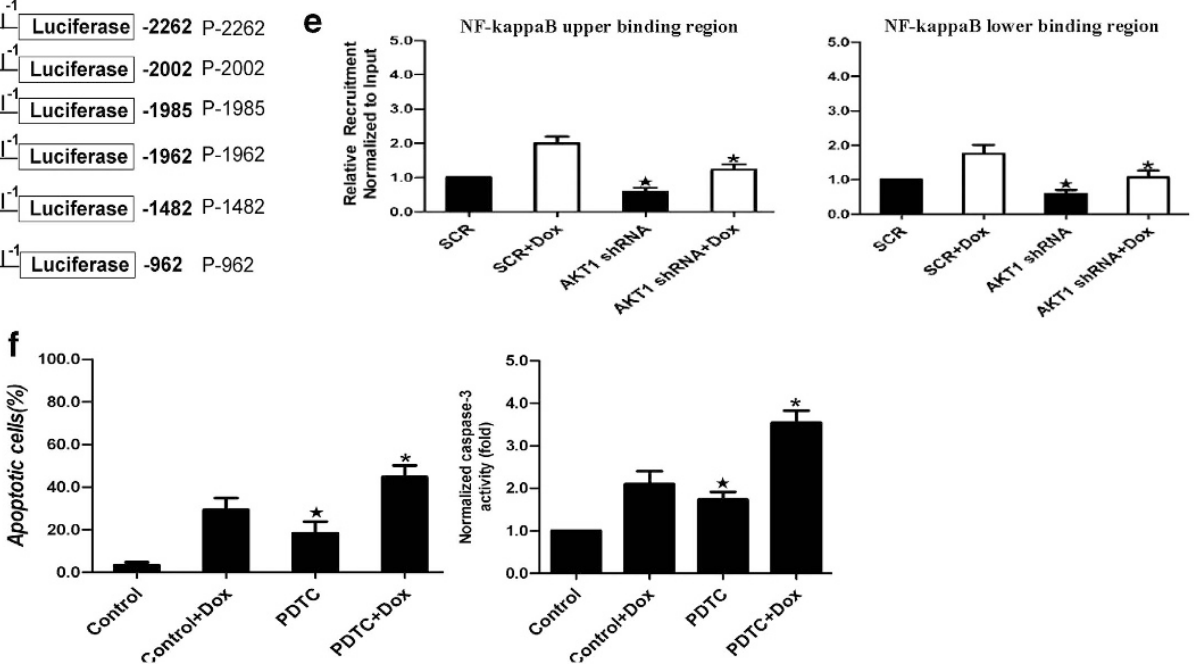

Figure $3 \mathrm{p} 65 / \mathrm{NF} F_{\kappa} \mathrm{B}$ bound to the Notch1 promoter and regulated the transcription of Notch1 gene. (a) The human Notch1 promoter sequence. (b) The schematic diagram of constructs with different $5^{\prime}$ upstream deletions. (c) Luciferase activity of the deleted constructs in MKN-28 cells. After transfection of reporter gene, cells were treated by doxorubicin $(3 \mu \mathrm{M}, 12 \mathrm{~h})$ with or without pretreatment with PDTC or infection of Akt1 shRNA lentivirus and p65 siRNA. All transfection experiments were repeated three times, and luciferase activity was normalized to the Renilla minimal reporter. Mean data \pm S.D. were results from three different experiments. ${ }^{\star} P<0.05{ }^{* \star} P<0.01$, cells with DOX treatment versus same cells without DOX treatment; ${ }^{\star} P<0.05,{ }^{\star}{ }^{\star} P<0.01$, PDTC + DOX group or AKT1 shRNA + DOX group versus DOX group or SCR shRNA + DOX group; $\# P<0.05$, \#\#P<0.01, p65 siRNA + DOX group versus Control siRNA + DOX group. (d) EMSA analysis for DNA binding activity of the upper and lower NF- $k B$ sites (NF- $\kappa$ B up and NF- $\kappa$ B low) in the Notch1 promoter of MKN-28 cells. Excess cold consensus NF- $\kappa$ B probe and anti- NF- $\kappa B$ ( $p 50$ and p65) were added 10 min before binding reaction. Arrows indicate NF- $\kappa$ B specific binding or supershift bands. (e) Recruitment of NF- $\kappa B$ to the Notch1 promoter. Data were presented as the relative amount of immunoprecipitated DNA normalized to input as measured by quantitative real-time PCR. The data for SCR samples were arbitrarily set as $1 .{ }^{\star} P<0.05$, versus SCR shRNA group; ${ }^{*} P<0.05$, versus SCR shRNA + Dox group. (f) Effect of PDTC $(50 \mu \mathrm{M})$ pretreatment $(2 \mathrm{~h})$ on doxorubicin $(3 \mu \mathrm{M})$ induced apoptosis and caspase-3 activity. ${ }^{\star} P<0.05$, versus Control group; ${ }^{\star} P<0.05$, versus Control + Dox group. All experiments were performed in triplicate 
a

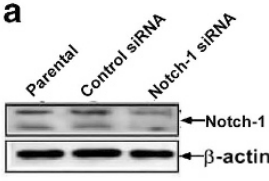

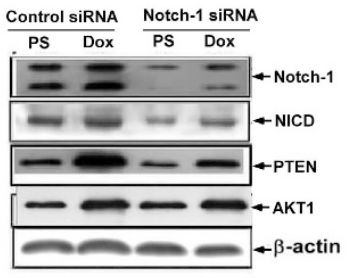

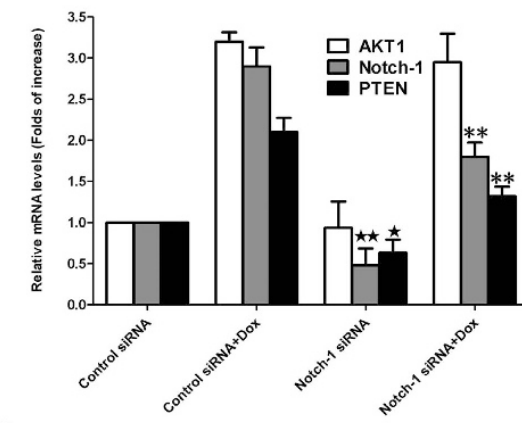

C

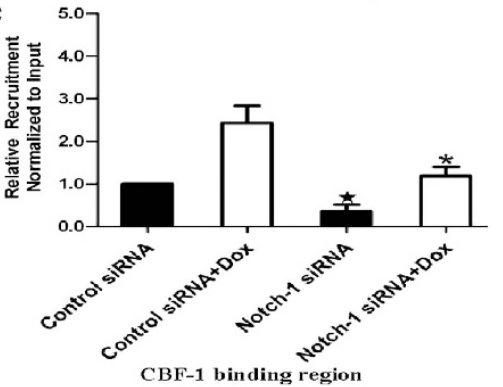

b

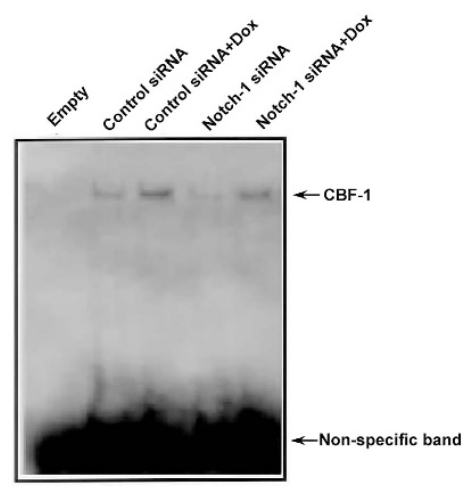

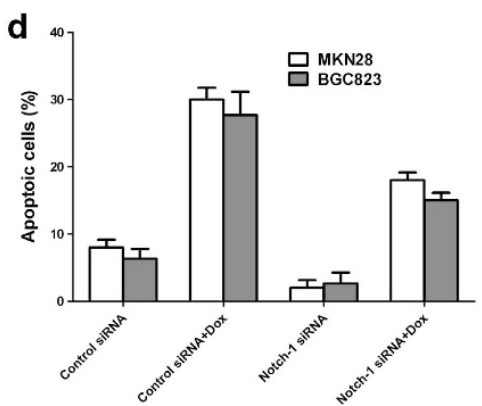

Figure 4 Notch1 regulated PTEN expression through CBF-1 and had a pro-apoptotic role in gastric cancer cells. (a) Lysate from MKN-28 cells (parental), MKN-28 cells transfected with control siRNA or Notch1 siRNA were analyzed by anti-Notch1 blotting. The MKN-28 cells transfected with control siRNA or Notch-1 siRNA were treated with PS or $3 \mu \mathrm{M}$ doxorubicin for $12 \mathrm{~h}$, respectively. The protein and mRNA levels of AKT1, Notch1 and PTEN were detected by immunoblotting and real-time RT-PCR. Immunoblotting results of $\beta$-actin were used to show equal loading. Values are the mean \pm S.D. from three different experiments. ${ }^{\star} P<0.05,{ }^{\star}{ }^{\star} P<0.01$, versus Control siRNA group; ${ }^{*} P<0.01$ versus Control siRNA + Dox group. (b and $\mathbf{c}$ ) The MKN-28 cells and MKN-28 cells transfected with control siRNA or Notch1 siRNA were treated with $\mathrm{PS}$ or $3 \mu \mathrm{M}$ doxorubicin for $12 \mathrm{~h}$, respectively. The DNA binding capability of CBF-1 on PTEN minimal promoter was detected by EMSA and ChIP analysis. ${ }^{\star} P<0.05$, versus Control siRNA group; ${ }^{*} P<0.05$ versus Control siRNA + Dox group. (d) BGC-823 cells and MKN-28 cells were transfected with control siRNA or Notch1 siRNA and then were treated with PS or $3 \mu \mathrm{M}$ doxorubicin for $12 \mathrm{~h}$, respectively. Cell apoptosis were determined by flow cytometry. Values are the mean \pm S.D. from experiments in triplicate

As shown in Figure 5a, strong expression of Notch1 and PTEN were visible in the cytoplasm normal gastric mucosal cells, whereas no or very weak expression of Notch1 and PTEN could be observed in foci of gastric cancer. Statistical analysis (Supplementary Table S4) demonstrated the Notch1 expression correlated with that of PTEN in gastric cancer tissues and the paired normal mucosa $(P<0.01)$. To further confirm the above results, the expression of Notch1 and PTEN were also determined in 12 fresh gastric cancer and the paired normal mucosa using immunoblotting (Figure 5b). Our data showed that Notch1 expression was obviously decreased in 11 tumor tissues; only one case $(\mathrm{C} 1, \mathrm{~N} 1)$ did not show the obvious difference. In 10 of the 12 cases, Notch1 expression fitted very well with the protein level of PTEN. These results also support the notion that Notch1 regulates PTEN expression and has a role as a tumor suppressor in gastric cancer.

Doxorubicin-induced PTEN expression has a pro-apoptotic function in gastric cancer cells. To further confirm that PTEN is a downstream target of $\mathrm{AKT} 1, \mathrm{NF}_{\kappa} \mathrm{B}$, and Notch1, the PTEN promoter luciferase activity was examined in this study. As shown in Figure 6a, doxorubicin promoted the PTEN transcription in MKN-28 cells. The constitutive and doxorubicin-induced PTEN transcriptions were inhibited by PDTC, AKT1 shRNA, and Notch1 siRNA (Figure 6a). To explore the role of PTEN expression induced by doxorubicin, constitutive expression of PTEN was knocked down by siRNA. As shown in Figure 6b, PTEN knockdown significantly inhibited both basal and induced apoptosis in gastric cancer cells, whereas introduction of wild-type PTEN plasmid promoted both basal and induced apoptosis (Figure 6c). All these revealed that in gastric cancer cells doxorubicin promoted apoptosis at least partly through induction of PTEN expression.

\section{Discussion}

Enhanced AKT kinase activity and subsequent downstream signal transduction is now acknowledged to have an important role in chemoresistance of human malignancy. ${ }^{27-29}$ However, the mechanism for the regulation of AKT gene expression and its contribution to chemoresistance is largely unknown. It is noteworthy that Park et al. ${ }^{30}$ characterized human AKT1 

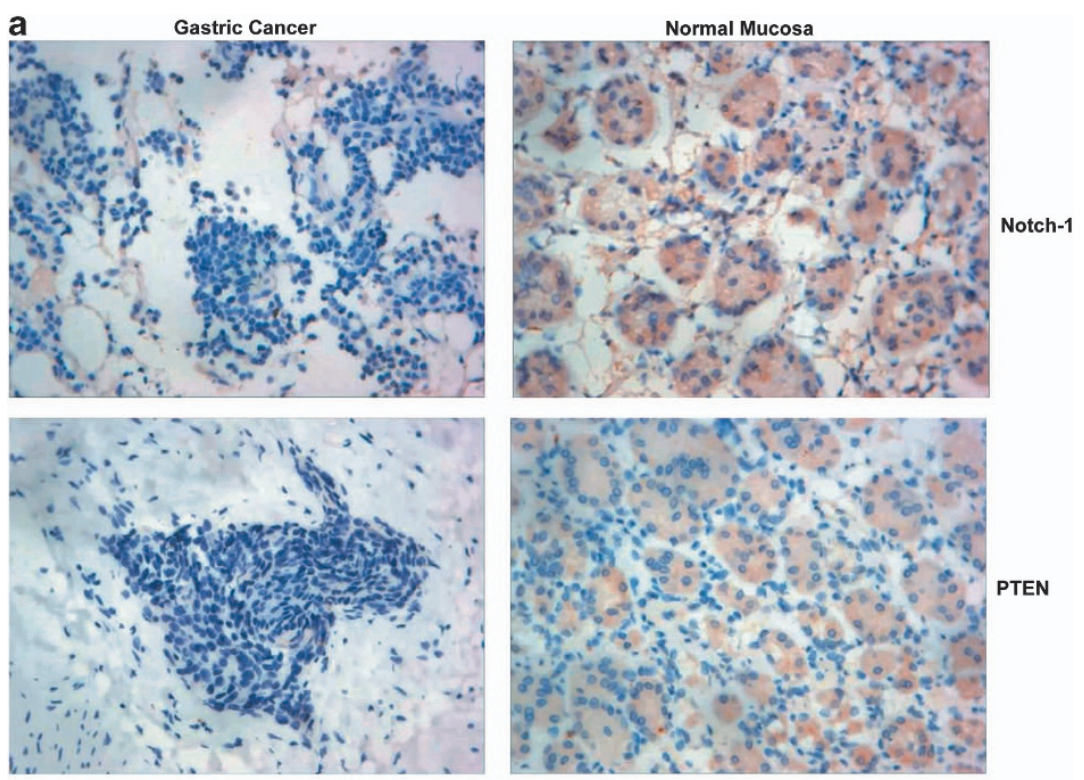

b

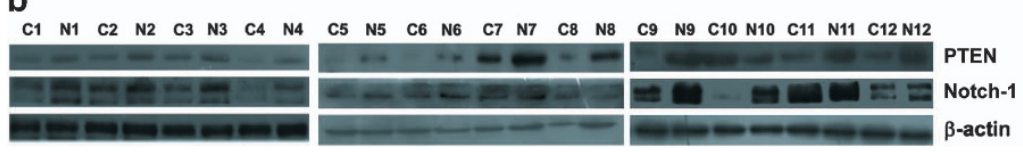

Figure 5 Lack of Notch1 and PTEN expression in gastric cancer tissues. (a) Immunohistochemical analysis of Notch1 and PTEN expression in gastric cancer and paired normal mucosa. ( $\times 400$ magnification). (b) The expression of Notch1 and PTEN in representative paired tissues from gastric cancer and adjacent normal mucosa detected by immunoblotting. $\mathrm{N}$, normal mucosa; $\mathrm{C}$, cancer. Immunoblotting result of $\beta$-actin is used to show equal loading

promoter and reported that AKT1 is a direct target gene of STAT3 (a known transcription factor), while Madamanchi et al. ${ }^{31}$ observed that JAK2/STAT3 pathway could be activated by ROS. In this study, we demonstrate that doxorubicin treatment increased ROS content and promoted AKT1 expression in gastric cancer cells (Supplementary Figure S1). Inhibition of ROS obviously downregulated the phosphorylation of JAK2 and STAT3, blocked the binding of STAT3 on AKT1 DNA promoter, and also inhibited AKT1 expression (Supplementary Figure S1). These results support the notion that doxurubicin stimulates the JAK2/STAT3 pathway by increasing the ROS content in gastric cancer cells, and the JAK2/STAT3 activation further upregulates the transcription of AKT1.

AKT1 regulates a number of downstream effectors involved in chemoresistance of gastric cancer. ${ }^{9}$ Among them, NF $\kappa \mathrm{B}$ has been proposed as a potential therapeutic target for overcoming chemoresistance. ${ }^{32}$ It has been shown that $\mathrm{NF}_{\kappa} \mathrm{B}$ increases Notch1 activity indirectly, by increasing the expression of Notch ligand Jagged1 in HeLa, lymphoma, and myeloma cells. ${ }^{33}$ However, Bedogni et al. ${ }^{19}$ showed that in melanoma cells AKT1 regulated Notch1 by increasing Notch1 transcription through the activity of $\mathrm{NF}_{\kappa} \mathrm{B}$. Our findings strongly support the observation of Bedogni et al. ${ }^{19}$ In our series, decreased expression or activity of AKT1 has been observed to inhibit both constitutive and induced Notch1 mRNA and protein level in cultured gastric cancer cell line. Similar results have been achieved in nude mice bearing gastric cancer xenograft. In addition, inhibition of $\mathrm{NF}_{\kappa} \mathrm{B}$ activity can block the active AKT1 introduction-induced
Notch1 expression. All these suggest that AKT1 mediates Notch 1 transcription through $\mathrm{NF}_{\kappa} \mathrm{B}$.

To further explore the role of $\mathrm{NF} \kappa \mathrm{B}$ on Notch1 transcription, the Notch-1 promoter sequence upstream of the transcription initiation start site has been cloned and sequenced. Putative transcription factor binding sites were shown to be located in the region. These included Sp-1, RREB-1, HLF, MZF-1, c-myc, p300, and $\mathrm{NF}_{\kappa} \mathrm{B}$. Two $\mathrm{NF}_{\kappa} \mathrm{B}$ binding sites (from -1978 to -1969 site; from -1995 to -1986 ) has been identified in Notch1 DNA promoter region. Dual-luciferase assay clearly demonstrated that decreased or deleted $\mathrm{NF}_{\kappa} \mathrm{B}$ binding sites could downregulate or even block the doxorubicin-induced Notch1 transcription; these results suggest that $\mathrm{NF} \kappa \mathrm{B}$ has a positive regulation role on Notch1 transcription. EMSA and ChIP analyses further show that p65 and p50 binds to the Notch-1 $5^{\prime}$ flanking region.

In human cancer cells, Notch1 acts as either a tumor suppressor or an oncogene. These paradoxical functions indicate that the role of Notch signaling is dependent on its cellular context. ${ }^{14,22-26}$ In many types of malignancy, including pancreatic cancer, colon cancer, non-small cell lung cancer, cervical cancer, renal cell carcinoma, and several lymphomas, Notch1 prevents differentiation and inhibits apoptosis. ${ }^{34}$ These suggest a potential oncogenic role of Notch1. Conversely, Notch1 signaling is very minimal or absent in prostate cancer, small-cell lung cancer, pancreatic carcinoid, and medullary thyroid cancer. ${ }^{35}$ Our present study shows that Notch1 expression in human gastric cancer tissue is much less than in paired normal gastric mucosa. The Notch1 expression is minimal or absent in the foci of gastric 


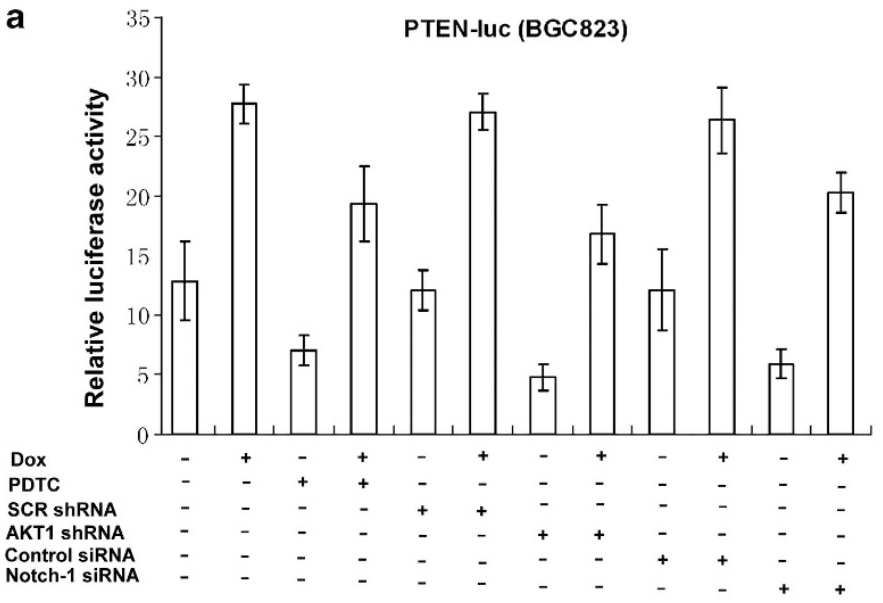

b
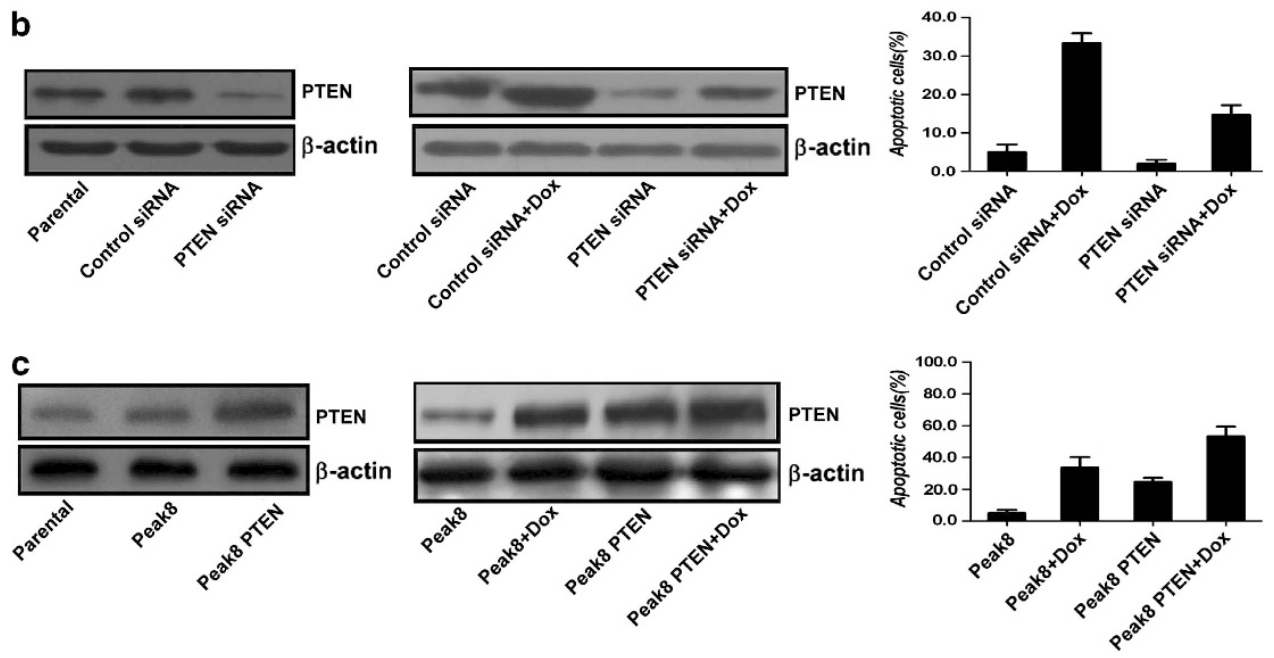

Figure 6 Doxorubicin-induced PTEN expression had a pro-apoptotic function in gastric cancer cells. (a) PTEN transactivation was mediated by NF $\kappa$ B, AKT1, and Notch1. MKN-28 cells were transfected for $9 \mathrm{~h}$ with the PTEN-luc reporter construct. Some cells were transfected together with control or Notch1 siRNA. Twenty-four hours later, cells were either left or pretreated with $10 \mu \mathrm{M}$ PDTC for $1 \mathrm{~h}$, left untreated or treated with $3 \mu \mathrm{M}$ doxorubicin for an additional 12-h period, after which the luciferase activity was determined. The MKN-28 cells expressing lentiviral SCR shRNA or lentiviral AKT1 shRNA were also transfected with PTEN-luc reporter construct followed by treatment with or without $3 \mu \mathrm{M}$ doxorubicin, after which the luciferase activity was determined. (b) Knockdown of PTEN by siRNA inhibited the basal and doxorubicin-induced cell apoptosis in gastric cancer cells. (c) Upregulation of PTEN expression by wild-type PTEN plasmid transfection promoted cell apoptosis in gastric cancer cells

cancer. Interference of Notch1 expression with siRNA significantly decreases the basal and induced cell apoptosis in cultured gastric cancer cells. All these indicate an anticancer role of Notch1 in gastric cancer.

It has been widely accepted that PTEN is the upstream and negative regulator of AKT pathway. ${ }^{36}$ However, $\mathrm{Yu}$ et al. ${ }^{12}$ showed that IGF-1-activated AKT led to phosphorylation of EGR1 followed by sumoylation of EGR1 by ARF, thereby producing a new modified molecule that directly transactivates the PTEN promoter. In gastric cancer cells, our data also show that there exists a feedback loop between AKT1 and PTEN both in in vitro or in vivo experiments: decreased AKT1 expression or activity downregulate PTEN transcription and expression. Conversely, our previous results ${ }^{9}$ have already suggested that PTEN downregulates basal and anti-cancer drug-induced AKT activity in cultured gastric cancer cells. Here in nude mice xenograft gastric cancer model, increased PTEN expression is described to inhibit the constitutive and inducible AKT1 phosphorylation without affecting the total AKT1 expression.

Our present data also demonstrate that knockdown of AKT1 decreases DNA binding capability of CBF-1 on PTEN minimal promoter and inhibition of $\mathrm{NF} \kappa \mathrm{B}$ blocks active AKT1 introduction-induced PTEN transcription and expression. Because CBF-1 is the main transcriptional effector of Notch1 receptor activation, ${ }^{20}$ these data indicate that $A K T 1 / N F \kappa B$ signal may regulate PTEN expression through Notch1.

Just like its role in tumorigenesis, the Notch1 acts as either positive or negative regulator of PTEN expression likely depending on the tissue or cell type. Whelan et al. ${ }^{14,15}$ indicated that in prostate cancer cells and 293 cells Notch1 promoted PTEN gene expression through binding of the CBF-1 transcription factor to the PTEN minimal promoter, while in T-ALL cells Palomero et al. ${ }^{35}$ described that PTEN expression was decreased by Notch1 signaling, which was mediated by binding of the negative regulator Hes- 1 to the PTEN promoter. We report herein that in gastric cancer cells siRNA knockdown 
of Notch1 downregulates constitutive and induced PTEN gene transcription and expression. Meanwhile, Notch1 knockdown decreases the binding of $\mathrm{CBF}-1$ on minimal promoter of PTEN. It is suggested that CBF-1 functions as a Notchresponsive transcriptional switch. ${ }^{20}$ In the absence of Notch1 activation, it acts as a transcriptional repressor by forming a repression complex, which includes Skip, SMRT/N-CoR, and HDAC1. ${ }^{20,37,38}$ Binding of intracytoplasmic Notch1 to CBF-1 and/or Skip displaces SMRT/N-CoR and HDAC1 and then recruits $\mathrm{MAML}, \mathrm{CBP} / \mathrm{p} 300$, and histone acetyl transferases. ${ }^{20,37,38}$ All these convert the CBF-1 complex into a transcriptional activation complex. ${ }^{20,37,38}$ Herein, our data suggest the role of Notch1 on regulation of PTEN transcription in gastric cancer cells, which fits very well with reports of Whelan et al. ${ }^{14}$ In addition, our data describe a statistical correlation between the expression of Notch1 and PTEN in gastric cancer and paired normal mucosa. This further supports the notion mentioned above. However, expression of Notch1 and PTEN are further influenced by the presence and activity of growth factors, upstream kinases and antagonists. Therefore, it is not surprising that we detected a strong staining of both Notch1 and PTEN in some samples, whereas in others high Notch1 levels did not correspond to the PTEN state.

Our previous results have suggested that the constitutive and inducible PI3K/AKT activities involve in chemoresistance of gastric cancer cells through activation of $\mathrm{NF}_{\kappa} \mathrm{B}$, phosphorylation of forkhead transcription factors, and mediation of caspase activities. ${ }^{9}$ In the present study, our results demonstrate that inhibition of AKT1 phosphorylation by PI3K inhibitor or upregulation of PTEN sensitize the gastric cancer cells to anti-cancer drug. Very interestingly, in in vitro and in vivo experiments AKT1 shRNA lentivirus, which decreases both expression and phosphorylation of AKT1, seems to have better effect on inducing apoptosis and inhibiting growth of gastric cancer cells. It is well acknowledged that the expression of a kinase is not necessarily a reflection of its activity level. However, our previous results showed strong staining of both total AKT1 and activated AKT1 (phosphorylated at residue 473) in gastric cancer samples. ${ }^{9}$ In the present study, the level of AKT1 phosphorylated at residue 473 also runs in parallel with the total level of AKT1 after treatment of doxorubicin in five gastric cancer cell lines and nude mice bearing xenograft gastric cancer (Supplementary Figure S2). All these indicate that inhibition of AKT1 on the transcriptional level may result in changes of AKT1 activity and consequently affect downstream effectors and finally sensitize the gastric cancer cells to anti-cancer drugs. This might be the plausible explanation that knockdown of AKT1 expression has the better effect on overcoming chemoresistance than only inhibition of AKT1 activities (Figure 2d).

It has also been reported that p53 regulates the PTEN gene expression. ${ }^{39}$ In our series, doxorubicin also increases PTEN transcription in the MKN-28 cells lacking functional p53 (Figure 1a). In BGC-823 cells, which contain wild type p53 protein, incubation of PTF- $\alpha$, a p53 inhibitor did not inhibit the constitutive and induced PTEN transcription and expression (data not shown). Our observations permit us to rule out the hypothesis that doxorubicin may be directly regulating p53, which in turn regulates PTEN in gastric cancer.

\section{Materials and Methods}

Tissue specimens. The matched tissue samples of primary gastric cancer and adjacent normal gastric mucosa from the same patient were collected from 22 patients (14 were male and 8 were female) of gastric cancer undergoing surgical resection at the Renming Hospital, Wuhan University (Wuhan, China) from 2009 to 2010. Written informed consent was obtained from each patient. Adjacent normal gastric mucosa specimens were obtained from the sites $\sim 5-10-\mathrm{cm}$ apart from the primary tumors. All tissues were snap-frozen in liquid nitrogen and stored at $-80^{\circ} \mathrm{C}$. Each case was reviewed by two experienced histopathologists. All patients had received neither chemotherapy nor radiation therapy before tumor resection.

Antibodies and reagents. Antibodies to CBF-1, PTEN, Notch1, AKT1, $\beta$-actin, p53, p65, p50, JAK2, and STAT3 were from Santa Cruz Biotechnology (Dallas, TX, USA). Antibodies to phospho-AKT1, phospho-JAK2, and phospho-STAT3 were from Upstate Biotechnology (Lake Placid, NY, USA). Antibody to NICD was from Cell Signaling (Danvers, MA, USA). Horseradish peroxidase-labeled secondary antibodies and chemiluminescence reagents were from Pierce, Thermo Scientific (Rockford, IL, USA). Fluorescent probes were from Molecular Probes (Eugene, OR, USA). LY294002, PDTC and N-acetyl-L-cysteine were from Calbiochem (Merck KGaA, Darmstadt, Germany). Doxorubicin was purchased from ALEXIS Biochemicals (San Diego, CA, USA). siRNA for human Notch1, p65 and PTEN, and control siRNA were from Santa Cruz Biotechnology.

Cell culture. Gastric cancer cell lines MKN-28, MKN-45, AGS, MKN-28, SGC-7901, and BGC-823 were maintained at $37^{\circ} \mathrm{C}$ in RPMI 1640 medium, supplemented with $10 \%$ fetal bovine serum, $100 \mathrm{U} / \mathrm{ml}$ of penicillin sodium, and $100 \mu \mathrm{g} / \mathrm{ml}$ of streptomycin sulfate in a humidified atmosphere containing $5 \% \mathrm{CO}_{2}$ and $95 \%$ air.

Lentiviral constructs and cell infection. For knockdown of human AKT1, combined shRNA and GFP protein expression was achieved using pGCSIL-GFP (Shanghai GeneChem, Shanghai, China) with the sense primer: 5'-CCGGGAGGCCAAGTCCTTGCTTTCAttcaagagaTGAAAGCAAGGACTTGGCCT CTTTTTG-3' and the anti-sense primer: 5'-AATTCAAAAAGAGGCCAAGTCC TTGCTTTCAtctcttgaaTGAAAGCAAGGACTTGGCCTC-3'. Primer encompasses the end of the U6 promoter, lower case letters represent the shRNA loop. A scrambled (Scr) shRNA was used as negative control. The recombinant virus was packaged using Lentivector Expression Systems (Shanghai GeneChem). MKN-28 cells were infected by Enhanced infection solution and cultured in RPMI-1640 medium containing 10\% FBS. After 1 week, GFP-positive cells were sorted by a flow cytometry (Becton Dickinson, Helmetta, NJ, USA). Experiments were performed with sorted GFP ${ }^{+}$cells (purity, $>97 \%$ ).

Generation, selection, and analysis of transfectants. Cells were transfected with the expression vectors or with empty plasmids as control using Lipofectamine 2000 reagent (Invitrogen, Paisley, UK). One day after transfection, cells were placed into the selection medium containing $0.5 \mathrm{mg} / \mathrm{ml} \mathrm{G418}$ (Life Technologies, Inc., Carlsbad, CA, USA). Fourteen days after selection, individual G418-resistant colonies were subcloned. Protein expression was analyzed by immunoblotting.

Expression vectors and luciferase reporter gene constructs. The PEAK8-PTEN plasmid was kindly provided by Dr. HY Li (Department of Gastroenterology, Shenyang General Hospital of PLA, Shenyang, China). The PTEN/pGL2-Basic reporter (PTEN-LR) was constructed by PCR cloning the PTEN promoter (GenBank AF067844) into the Xho I and Hind III sites of PGL2-basic (Promega, Madison, WI, USA) as described before. ${ }^{16}$ The Notch1 promoter regions $-2262 /-1$ (numbered relative to the ATG) were amplified by PCR from human genomic DNA with the primer pairs $5^{\prime}$-CCCCCTCATCCCTGGCTTCTC- $3^{\prime}$ and $5^{\prime}$-GCCTCCCCACCGGCTGCCCTC- $3^{\prime}$ and subcloned into the pGL4 vector (Promega) using the Kpnl/Nhel sites. The 2002/-1, 1985/-1, 1962/-1, 1482/-1, and 962/-1 Notch1 promoter regions were amplified by PCR from the 2262pGL4 clone using the reverse primer $5^{\prime}$-GCCTCCCCACCGGCTGCCCTC- $3^{\prime}$ in combination with the following forward primers: 5'-CAGACCAGGGGAGACCCCCTAT-3', 5'-CCTATCCAGGGATCCCCTCCT-3' 5'-CCTCCCAGGCCGCCCCTCCGC-3', 5'-TGGCAAGAGGTGTGCCAGGAA-3' and 5'-CCTTGGGGGAGCGGGGCACA-3', respectively. The inserts were subsequently subcloned in the pGL4 vector using the Kpnl/Nhel sites. All pGL4-plasmids with putative Notch1 promoter fragments 
were sequenced in both directions at the UNC-CH automated DNA sequencing facility.

Promoter activity assays. Cells were plated onto 12-well dishes and transfected with the PGL4 luciferase reporter plasmid $(0.5 \mu \mathrm{g} / \mathrm{well})$, using Lipofectamine 2000 (Invitrogen) according to the manufacturer's instructions. For normalization of luciferase activity, the pRL-TK control vector containing the herpex simplex virus thymidine kinase promoter encoding Renilla luciferase was used, resulting in its constitutive expression in a variety of cell types (Promega). The pRL-TK vector was used $(0.05 \mu \mathrm{g} /$ well) together with pGL4 plasmids for co-transfection. For all experiments, cells were cultured for $48 \mathrm{~h}$ after transfection and lysed with the Passive Lysis Buffer (Promega). Lysates were analyzed using the Dual-Luciferase Reporter Assay System kit (Promega). Luminescence was measured on an AutoLumat LB 953 Luminometer (Berthold Technologies, Bad Wildbad, Schwarzwald, Germany). All experiments were repeated at least three times.

Immunoblotting analysis. Cells were solubilized in ice-cold lysis buffer $(1 \times$ PBS (phosphate-buffered saline), $1 \%$ Igepal CA-630, 0.5\% sodium deoxycholate, $0.1 \%$ SDS, $10 \mathrm{mg} / \mathrm{ml}$ phenylmethylsulfonyl fluoride, $100 \mathrm{mM}$ sodium orthovanadate, $60 \mu \mathrm{g} / \mathrm{ml}$ aprotinin, $10 \mu \mathrm{g} / \mathrm{ml}$ trypsin inhibitor, and $10 \mu \mathrm{g} / \mathrm{ml}$ leupeptin). After $10 \mathrm{~min}$ centrifugation at $10000 \mathrm{~g}$ at $4{ }^{\circ} \mathrm{C}$, the supernatants were transferred into new micro-centrifuge tubes, and the protein concentration of the supernatant was measured using the BCA protein assay (Pierce), then stored under $-20^{\circ} \mathrm{C}$. Fifty micrograms of the cell lysates were separated on SDS-polyacrylamide gel. Following SDS-PAGE, proteins were transferred to nitrocellulose membranes. For detection of proteins, membranes were blocked using $5 \%$ nonfat dried milk in Tris buffer containing $0.1 \%$ Tween (TBS-T) and then incubated at $4{ }^{\circ} \mathrm{C}$ overnight with specific antibodies diluted in TBS-T containing $5 \%$ non-fat milk. Bound primary antibodies to immunoreactive bands were visualized by enhanced chemoluminescence detection with horseradish peroxidaseconjugated anti-rabbit or anti-mouse antibodies.

RNA-extraction and real time RT-PCR. Total RNA was isolated using Trizol (Life Technologies, Inc.), following the manufacture's instructions. Total RNA $(2 \mu \mathrm{g})$ was reversed transcribed using Superscript II (Life Technologies, Inc.), following the company's instructions. cDNA was used as a template in a real-time PCR reaction with specific primers (Supplementary Table S1). Relative expression levels were determined by comparing $\triangle$ Ct-values of AKT1, Notch1, or PTEN amplification in comparison with $\beta$-actin amplification of corresponding cDNA samples.

Electrophoretic mobility shift assay (EMSA). Nuclear extracts were prepared using the NE-PER Nuclear and Cytoplasmic Extraction Reagents (Pierce) following the manufacturer's instructions. All oligonucleotides (Supplementary Table S2) were hybridized with a complementary synthesized oligonucleotide and used in double-stranded form for biotin-labeling reactions. The DNA binding capability of CBF-1 was detected using a 70-bp probe spanning the PTEN minimal promoter from -1174 to $-1104 .^{15}$ EMSA was performed using the LightShift Chemiluminescent EMSA Kit (Pierce).

Chromatin immunoprecipitation (ChIP). Cells were plated in a 60-mm culture dish, cultured for $24 \mathrm{~h}$, fixed with formaldehyde, and then used to perform ChIP experiment. ChIP was performed with the ChIP assay kit (Millipore, Billerica, MA, USA), following the manufacturer's instructions. PCR was performed using primers (Supplementary Table S3) to the promoter region of AKT1, Notch1, or PTEN.

Apoptosis analysis. Cells suspended at each chosen time point after various concentrations of anti-cancer treatment were fixed with ice-cold $75 \%$ ethanol, washed twice with PBS, and incubated in $20 \mu \mathrm{g} / \mathrm{ml} \mathrm{RNase}$ A for $30 \mathrm{~min}$ at $37^{\circ} \mathrm{C}$. Subsequently, cells were stained with Annexin-V-Florescein and propidium iodide (PI) and measured for DNA content by means of a flow cytometry (Becton Dickinson).

Caspase-3 activity. A Caspase-3 Colorimetric Assay Kit (Nanjing Keygen Biotechnology, Nanjing, China) was used to measure the activity of caspase-3. Following the manufacturer's instruction, the six cell lines were seeded into the six-wells and cultured for $24 \mathrm{~h}$. Next, the cells were incubated in the presence or absence of $5 \mu \mathrm{g} / \mathrm{ml}$ cisplatin for an additional $24 \mathrm{~h}$. The cells were then harvested, resuspended in $50 \mu$ l of lysis buffer, and incubated on ice for
30 min At this point, the cellular debris was pelleted, and the lysates $(50 \mu \mathrm{l})$ were transferred to 96 -well plates. The lysates were added to $50 \mu \mathrm{l}$ of $2.0 \times$ reaction buffer along with $5 \mu$ l of Caspase-3 Substrate and incubated for $4 \mathrm{~h}$ at $37^{\circ} \mathrm{C}$ in a $5 \% \mathrm{CO}_{2}$ incubator. The activities were quantified spectrophotometrically at a wavelength of $405 \mathrm{~nm}$.

Immunohistochemistry. Immunochemistry analysis was conducted as previously described. ${ }^{9}$ Immunoreactivities of PTEN and Notch-1 were graded as follows: ' - ' $0,0-4 \%$ of cells were stained; ' + ', $5-25 \%$ of cells were stained; ' ++ ', $>25-50 \%$ of cells were stained; and ' +++ ' $>50 \%$ of cells were stained.

The measurement of reactive oxygen species (ROS). MKN-28 cells were treated with doxorubicin for $12 \mathrm{~h}$. After washing with PBS, the cells were incubated with $2 \mu \mathrm{mol} / /$ DCFDA (Sigma, St. Louis, MO, USA) in PBS for $30 \mathrm{~min}$ at $37^{\circ} \mathrm{C}$. The excess probe was washed off with PBS, and the labeled cells were measured using flow cytometric analysis (Becton Dickinson).

Animal study. All animal studies were conducted according to the Chinese national guidelines for the care and use of laboratory animals. Four-to-6-week-old male BALB/c nude mice were inoculated with $2 \times 10^{6} \mathrm{MKN}-28$ cells at one flank in PBS containing 20\% Matrigel. Treatment was initiated when tumors reached $100 \mathrm{~mm}^{3}$. Tumor size was measured every other day with a caliper, and tumor volume was calculated by the following formula: (length $\times$ width $\left.^{2}\right) / 2$. The apoptosis in tumor was detected by TUNEL analysis. The cell proliferation in tumor was detected through immunohistostaining of Ki-67.

Data analysis. For cell culture experiments, mean values and S.D. of at least triplicate experimental points were calculated. Student's t-test was used to compare mean value differences. Differences between pairs of data were determined using an unpaired two-tailed Student's $t$-test. The distribution (negative to +++ ) of Notch-1 and PTEN tumor staining was evaluated using the Pearson's chi-square test.

\section{Conflict of Interest}

The authors declare no conflict of interest.

Acknowledgements. We thank Mr. Hong Xia for outstanding administrative support and excellent technical assistance in this work. This work was supported by grants from the National Natural Science Foundation of China (No. 30770967) and Program for New Century Talent of National Ministry of Education, China.

1. Basu B, Yap TA, Molife LR, de Bono JS. Targeting the DNA damage response in oncology: past, present and future perspectives. Curr Opin Oncol 2012; 24: 316-324.

2. Koo DH, Lee JL, Kim TW, Chang HM, Ryu MH, Yook Jh et al. Adjuvant chemotherapy with 5 -fluorouracil, doxorubicin and mitomycin-C (FAM) for 6 months after curative resection of gastric carcinoma. Eur J Surg Oncol 2007; 33: 843-848.

3. Kulke MH, Wu B, Clark JW, Enzinger PC, Lynch TJ, Vincitore M et al. A phase II study of doxorubicin, cisplatin, and 5-fluorouracil in patients with advanced adenocarcinoma of the stomach or esophagus. Cancer Invest 2006; 24: 229-234.

4. Galluzzi L, Larochette N, Zamzami N, Kroemer G. Mitochondria as therapeutic targets for cancer chemotherapy. Oncogene 2006; 25: 4812-4830.

5. Fulda S, Debatin KM. Extrinsic versus intrinsic apoptosis pathways in anticancer chemotherapy. Oncogene 2006; 25: 4798-4811.

6. Wen Y, Gorsic LK, Wheeler H, Ziliak D, Huang RS, Dolan MB. Chemotherapeutic-induced apoptosis: a phenotype for pharmacogenomics studies. Pharmacogenet Genomics 2011; 21: $476-488$

7. Hernandez-Aya LF, Gonzalez-Angulo AM. Targeting the phosphatidylinositol 3-kinase signaling pathway in breast cancer. Oncologist 2011; 16: 404-414.

8. Hay M. Interplay between FOXO, TOR, and Akt. Biochim Biophys Acta 2011; 1813: 1965-1970.

9. Yu HG, Ai YW, Yu LL, Zhou XD, Liu J, Li JH et al. Phosphoinositide 3-kinase/Akt pathway plays an important role in chemoresistance of gastric cancer cells against etoposide and doxorubicin induced cell death. Int J Cancer 2008; 122: 433-443.

10. Zhang S, Yu D. PI(3)king apart PTEN's role in cancer. Clin Cancer Res 2010; 16: 4325-4530.

11. Davies MA, Koul D, Dhesi H, Berman R, McDonnell TJ, McConkey D et al. Regulation of Akt/PKB activity, cellular growth, and apoptosis in prostate carcinoma cells by MMAC/PTEN. Cancer Res 1999; 59: 2551-2556.

12. Yu J, Zhang SS, Saito K, Williams S, Arimura Y, Ma Y et al. PTEN regulation by Akt-EGR1ARF-PTEN axis. EMBO J 2009; 28: 21-33. 
13. Kim J, Lee YH, Kwon TK, Chang JS, Chung KC, Min DS. Phospholipase D prevents etoposide-induced apoptosis by inhibiting the expression of early growth response-1 and phosphatase and tensin homologue deleted on chromosome 10. Cancer Res 2006; 66 : 784-793.

14. Whelan JT, Kellogg A, Shewchuk BM, Hewan-Lowe K, Bertrand FE. Notch-1 signaling is lost in prostate adenocarcinoma and promotes PTEN gene expression. J Cell Biochem 2009; 107: 992-1001.

15. Whelan JT, Forbes SL, Bertrand FE. CBF-1 (RBP-J kappa) binds to the PTEN promoter and regulates PTEN gene expression. Cell Cycle 2007; 6: 80-84.

16. Chappell WH, Green TD, Spengeman JD, McCubrey JA, Akula SM, Bertrand FE. Increased protein expression of the PTEN tumor suppressor in the presence of constitutively active Notch-1. Cell Cycle 2005; 4: 1389-1395.

17. Chillakuri CR, Sheppard D, Lea SM, Handford PA. Notch receptor-ligand binding and activation: Insights from molecular studies. Semin Cell Dev Biol 2012; 23: 421-428.

18. Hansson EM, Lendahl U, Chapman G. Notch signaling in development and disease. Semin Cancer Biol 2004; 14: 320-328.

19. Bedogni B, Warneke JA, Nickoloff BJ, Giaccia AJ, Powell MB. Notch1 is an effector of Akt and hypoxia in melanoma development. J Clin Invest 2008; 118: 3660-3670.

20. Del Bianco C, Aster JC, Blacklow SC. Mutational and energetic studies of Notch-1 transcription complexes. J Mol Biol 2008; 376: 131-140.

21. Nefedova Y, Cheng P, Alsina M, Dalton WS, Gabrilovich D. Involvement of Notch-1 signaling in bone marrow stroma-mediated de novo drug resistance of myeloma and other malignant lymphoid cell lines. Blood 2004; 103: 3503-3510.

22. Eliasz S, Liang S, Chen Y, De Marco MA, Machek O, Skucha S et al. Notch-1 stimulates survival of lung adenocarcinoma cells during hypoxia by activating the IGF-1R pathway. Oncogene 2010; 29: 2488-2498

23. Hao L, Rizzo P, Osipo C, Pannuti A, Wyatt D, Cheung LW et al. Notch-1 activates estrogen receptor-alpha-dependent transcription via IKKalpha in breast cancer cells. Oncogene 2010; 29: 201-213.

24. Meng RD, Shelton CC, Li YM, Qin LX, Notterman D, Paty PB et al. gamma-Secretase inhibitors abrogate oxaliplatin-induced activation of the Notch-1 signaling pathway in colon cancer cells resulting in enhanced chemosensitivity. Cancer Res 2009; 69: 573-582.

25. Sjölund J, Johansson M, Manna S, Norin C, Pietras A, Beckman S et al. Suppression of renal cell carcinoma growth by inhibition of Notch signaling in vitro and in vivo. J Clin Invest 2008; 118: 217-228

26. Kunnimalaiyaan $\mathrm{M}$, Traeger $\mathrm{K}$, Chen $\mathrm{H}$. Conservation of the Notch1 signaling pathway in gastrointestinal carcinoid cells. Am J Physiol Gastrointest Liver Physiol 2005; 289: G636-G642.

27. Li Z, Oh DY, Nakamura K, Thiele CJ. Perifosine-induced inhibition of Akt attenuates BDNF/ TrkB-induced chemoresistance in neuroblastoma in vivo. Cancer 2011; 117: 5412-5422.
28. Chen W, Bai L, Wang X, Xu S, Belinsky SA, Lin Y. Acquired activation of the Akt/cyclooxygenase-2/Mcl-1 pathway renders lung cancer cells resistant to apoptosis. Mol Pharmacol 2010; 77: 416-423.

29. Abedini MR, Muller EJ, Bergeron R, Gray DA, Tsang BK. Akt promotes chemoresistance in human ovarian cancer cells by modulating cisplatin-induced, p53-dependent ubiquitination of FLICE-like inhibitory protein. Oncogene 2010; 29: 11-25.

30. Park S, Kim D, Kaneko S, Szewczyk KM, Nicosia SV, Yu H et al. Molecular cloning and characterization of the human AKT1 promoter uncovers its up-regulation by the Src/Stat3 pathway. J Biol Chem 2005; 280: 38932-38941.

31. Madamanchi NR, Li S, Patterson C, Runge MS. Reactive oxygen species regulate heatshock protein 70 via the JAK/STAT pathway. Arterioscler Thromb Vasc Biol 2001; 21: 321-326.

32. Li F, Sethi G. Targeting transcription factor NF-kappaB to overcome chemoresistance and radioresistance in cancer therapy. Biochim Biophys Acta 2010; 1805: 167-180.

33. Bash J, Zong WX, Banga S, Rivera A, Ballard DW, Ron Y et al. Rel/NF-kappaB can trigger the Notch signaling pathway by inducing the expression of Jagged1, a ligand for Notch receptors. EMBO J 1999; 18: 2803-2811.

34. Kunnimalaiyaan $\mathrm{M}$, Chen $\mathrm{H}$. Tumor suppressor role of Notch-1 signaling in neuroendocrine tumors. Oncologist 2007; 12: 535-542.

35. Palomero T, Dominguez M, Ferrando AA. The role of the PTEN/AKT pathway in NOTCH1-induced leukemia. Cell Cycle 2008; 7: 965-970.

36. Salmena L, Carracedo A, Pandolfi PP. Tenets of PTEN tumor suppression. Cell 2008; 133: 403-414.

37. Kao HY, Ordentlich P, Koyano-Nakagawa N, Tang Z, Downes M, Kintner C et al. A histone deacetylase corepressor complex regulates the Notch signal transduction pathway. Genes Dev 1998; 12: 2269-2277.

38. Hsieh JJ, Zhou S, Chen L, Young DB, Hayward SD. CIR, a corepressor linking the DNA binding factor CBF1 to the histone deacetylase complex. Proc Natl Acad Sci USA 1999; 96: 23-28.

39. Stambolic V, MacPherson D, Sas D, Lin Y, Snow B, Jang Y et al. Regulation of PTEN transcription by p53. Mol Cell 2001; 8: 317-325.

(c) (1) (2) (2) Death and Disease is an open-access journal published by Nature Publishing Group. This work is licensed under a Creative Commons Attribution-NonCommercialShareAlike 3.0 Unported License. To view a copy of this license, visit http://creativecommons.org/licenses/by-nc-sa/3.0/

\section{Supplementary Information accompanies this paper on Cell Death and Disease website (http://www.nature.com/cddis)}

